\title{
Postoperative nausea and vomiting
}

\author{
Young Eun Moon \\ Department of Anesthesiology and Pain Medicine, Seoul St. Mary’s Hospital, Catholic University College of Medicine, Seoul, Korea
}

Postoperative nausea and vomiting (PONV) is a long-standing issue, not a new concept in anesthesiology. Despite many studies over the last several decades, PONV remains a significant problem due to its complex mechanism. This review presents a summary of the mechanism underlying the pathogenesis of PONV, focusing on preventive treatment, particularly the use of new drugs. In addition, we discuss the latest meta-analysis results regarding correct clinical use of classic drugs. I also summarize the latest trends of postdischarge nausea and vomiting and the pharmacogenetics, which is attracting a great deal of attention from other medical fields in PONV-related studies. Finally, we discuss the drawbacks of existing studies on PONV and suggest a focus for future investigations. (Korean J Anesthesiol 2014; 67: 164-170)

Key Words: Postdischarge nausea and vomiting, Postoperative nausea and vomiting, Prevention.

\section{Introduction}

Postoperative nausea and vomiting (PONV) has attracted a great deal of attention since Kapur described it as the big "little problem" in 1991 [1]. PONV has long been an important issue in anesthesiology, and many well-designed randomized control trials (RCTs) and meta-analyses have been reported along with the development of new drugs. Despite analyses of risk factors and proposals for prophylactic management, PONV remains a significant problem in clinical settings, which can be attributed, at least in part, to the complex mechanism underlying the pathogenesis of PONV as well as the relative lack of concern regarding this issue by anesthesiologists. This review article discusses the latest study trends for PONV and guidelines proposed by experts for future PONV-related investigations.

\section{Mechanisms of PONV Pathogenesis}

The mechanisms responsible for the stimulation of nausea and vomiting are different-while nausea occurs due to a forebrain pathway, vomiting occurs due to a hindbrain central pattern generator [2]. Diverse stimuli stimulate an emetic center located in the medulla. This center receives various signals from visceral afferent nerves in the gastrointestinal tract, chemoreceptor trigger zone (CTZ), higher cerebral cortex, cerebellum, and vestibular apparatus. In particular, the CTZ located in the fourth ventricle of the brainstem lies outside the blood-brain barrier and is therefore exposed to drugs, such as inhalational anesthetics and opioids. Dopamine, opioid, histamine, acetylcholine, 5-hydroxytryptamine 3 (serotonin 3 ) receptors, and neurokinin-1 receptors have been shown to be related to the

Received: May 8, 2014. Accepted: May 14, 2014.

Corresponding author: Young Eun Moon, M.D., Ph.D., Department of Anesthesiology and Pain Medicine, Seoul St. Mary's Hospital, Catholic University College of Medicine, 222 Banpodaero, Seocho-gu, Seoul 137-040, Korea. Tel: 82-2-2258-6163, Fax: 82-2-537-1951, E-mail: 0910momo@naver.com

(c) This is an open-access article distributed under the terms of the Creative Commons Attribution Non-Commercial License (http:// creativecommons.org/licenses/by-nc/3.0/), which permits unrestricted non-commercial use, distribution, and reproduction in any medium, provided the original work is properly cited. 
emetic center, and these diverse stimuli suggest that treatment with combinations of different drugs will be essential to prevent PONV.

\section{PONV Risk Factors}

Apfel [3] proposed four clear risk factors associated with PONV, i.e., female gender, prior history of motion sickness and/ or PONV, non-smoker, and postoperative opioid treatment, and suggested that each factor increased risk by $20 \%$. In addition, Koivuranta et al. [4] reported five risk factors, i.e., duration of surgery $>1$ hour, female gender, prior history of motion sickness, prior history of PONV, and non-smoker. These relatively simple and clear scoring schemes have been used in many studies. Apfel et al. [5] selected 22 large-scale RCTs (total $n=95,154$ ) including only studies in $>500$ patients to evaluate which risk factors are independent predictors of PONV. The results indicated that the strongest patient-related predictors were female gender (odds ratio $[\mathrm{OR}]=2.57,95 \%$ confidence interval $[\mathrm{CI}]=$ 2.32-2.84) followed by prior history of motion sickness/PONV $(\mathrm{OR}=2.09,95 \% \mathrm{CI}=1.90-2.29)$, non-smoking status $(\mathrm{OR}=$ $1.82,95 \% \mathrm{CI}=1.68-1.98)$, history of motion sickness $(\mathrm{OR}=$ $1.77,95 \% \mathrm{CI}=1.55-2.04)$, and age $(\mathrm{OR}=0.88$ per decade, $95 \%$ $\mathrm{CI}=0.84-0.92)$. Anesthesia-related predictors included use of inhalation anesthetics $(\mathrm{OR}=1.82,95 \% \mathrm{CI}=1.56-2.13)$, period of anesthesia ( $\mathrm{OR}=1.46 / \mathrm{h}, 95 \% \mathrm{CI}=1.30-1.63)$, postoperative opioid use ( $\mathrm{OR}=1.39,95 \% \mathrm{CI}=1.20-1.60)$, and nitrous oxide use $(\mathrm{OR}=1.45,95 \% \mathrm{CI}=1.06-1.98)$. Type of surgery, preoperative fasting, and menstrual cycle were not significant factors related to PONV. In general, use of non-validated risk factors, particularly type of surgery, can cause confusion. For example, laparoscopic gynecological surgery has been suggested as a risk factor of PONV. However, patient-related factors (female gender, itself the strongest predictor of PONV) may have a greater effect on risk than the surgery itself. Thus, the inclusion of unclear factors can adversely affect the evaluation of PONV risk factors in patients and so care should be used in clinical fields and studies.

\section{Pharmacogenetics Associated with PONV}

The possible role of genetics in PONV has attracted attention along with the development of pharmacogenetics in opioids. This idea is based on the fact that opioids induce PONV. That is, pharmacogenetic studies on opioids indicated that PONV as a secondary outcome, as well as pain, are significantly related to genes. In this regard, the OPRM1 gene encoding opioid mu receptors have been studied most extensively. The risk of PONV is high in homozygous patients with the A118 variant of OPRM1. For example, individuals homozygous for the A118 genotype showed the lowest severity of pain and the highest incidence of nausea despite receiving smaller amounts of morphine by patient-controlled analgesia (PCA) [6]. Of course, most genetic studies associated with PONV have focused on opioid-induced nausea and vomiting (OINV), and not on symptoms occurring postoperatively. However, as opioids are obvious factors responsible for PONV, and there is increasing interest in PONV as a side effect related to PCA, genetic studies associated with PONV will provide a great deal of clinically useful information. The most common types of genetic study associated with PONV are those of the single nucleotide polymorphisms associated with neural signaling and transmitter receptors in the PONV system. Genes regarded as related to PONV or OINV include $5-\mathrm{HT}_{3}$ (subunit A and B) receptor [7], muscarinic type 3 receptor, dopamine type 2 receptors [8], catechol-o-methyl-transferase [9], alpha 2 adrenoceptors [10], adenosine triphosphate-binding cassette subfamily B member 1 [11], cytochrome P450 superfamily enzyme [12], and UDP-glucuronosyltransferase.

\section{Pharmacological Therapies}

As mentioned above, use of two or more drugs belonging to different classes is effective because of the complex mechanism underlying the pathogenesis of PONV. In particular, combination therapy is essential for high-risk patients. If PONV occurs, despite administration of antiemetics, rescue antiemetics should be selected from drugs belonging to a different class from that administered previously. It is therefore essential to have knowledge regarding the class of each drug and its mechanism of action. The doses of drugs in each class and their side effects are presented in Table 1.

\section{Cholinergic receptor antagonists}

Cholinergic receptor antagonists are among the oldest antiemetic drugs. They block muscarinic receptors in the cerebral cortex and pons to induce antiemetic effects. The most effective drug in this class, scopolamine, is a competitive inhibitor at postganglionic muscarinic receptors in the parasympathetic nervous system and acts directly on the central nervous system by antagonizing cholinergic transmission in the vestibular nuclei. This drug is applied with a transdermal patch because of its short half-life, and $1.5 \mathrm{mg}$ is secreted over a period of 72 hours. In a large-scale meta-analysis, prophylactic transdermal scopolamine was reported to significantly decrease PONV [13]. The side effects of scopolamine include dry mouth and visual disturbance. In addition, patients must not touch their eyes with their hands after handling a patch to prevent mydriasis [14]. 
Table 1. Doses and Side Effects of Antiemetics

\begin{tabular}{|c|c|c|}
\hline Drug & Dose & Side effects \\
\hline Cholinergic antagonists & & Dry mouth, drowsiness, impaired eye accommodation \\
\hline Scopolamine & Transdermal patch & \\
\hline Histamine antagonists & & Sedation, dry mouth, constipation \\
\hline Dimenhydrinate & $1-2 \mathrm{mg} / \mathrm{kg} \mathrm{IV}$ & \\
\hline Promethazine & $12.5-25 \mathrm{mg} \mathrm{IV}$ & \\
\hline Serotonin antagonists & & Headache, asymptomatic prolongation of electrocardiographic interval \\
\hline Ondansetron & $4-8 \mathrm{mg}$ IV & \\
\hline Dolasetron & $12.5 \mathrm{mg}$ IV & \\
\hline Granisetron & $0.35-1 \mathrm{mg} \mathrm{IV}$ & \\
\hline Ramosetron & $0.3 \mathrm{mg}$ IV & \\
\hline Tropisetron & $2 \mathrm{mg} I V$ & \\
\hline Palonosetron & $0.075 \mathrm{mg}$ IV & \\
\hline Dopamine antagonists & & Sedation, restlessness, extrapyramidal effects \\
\hline Metoclopramide & 10 mg IV & \\
\hline Droperidol & $0.25-0.625 \mathrm{mg} \mathrm{IV}$ & \\
\hline Phenothiazines & & Sedation, lethargy, skin sensitization \\
\hline Chlorpromazine & $10 \mathrm{mg}$ IV & \\
\hline $\mathrm{NK}_{1}$ antagonist & & Constipation, pruritus \\
\hline Aprepitant & $40 \mathrm{mg}$ PO & \\
\hline Corticosteroids & & Gastrointestinal upset, insomnia \\
\hline Dexamethasone & $4-5 \mathrm{mg}$ IV & \\
\hline
\end{tabular}

\section{Histamine receptor antagonists}

$\mathrm{H}_{1}$ histamine receptor antagonists have been shown to inhibit PONV. These drugs block acetylcholine receptors in the vestibular apparatus and histamine receptors in the solitary tract nucleus with anticholinergic properties. These agents are therefore relatively nonspecific compared to drugs in other classes and have anticholinergic properties. Studies on $\mathrm{H}_{1}$ receptor antagonists are limited, as compared to other antiemetics, but it was shown that these drugs are generally less effective than $5-\mathrm{HT}_{3}$ antagonists [2]. The side effects of histamine receptor antagonists include drowsiness, urinary retention, dry mouth, and blurred vision [14].

\section{Serotonin antagonists}

5- $\mathrm{HT}_{3}$ antagonists are the most common antiemetics used in the perioperative setting. These drugs peripherally block gut vagal afferents and act centrally in the area postrema. The most commonly used $5-\mathrm{HT}_{3}$ antagonist in the West is ondansetron, and this is also the best studied of this class of drugs. Many large-scale studies and Cochrane systematic reviews have indicated that preventive administration of ondansetron decreases PONV by $25 \%[15,16]$. A recent investigation of ondansetron led to new FDA warnings regarding its use in patients with prolonged QT interval [17]. Other $5-\mathrm{HT}_{3}$ antagonists include granisetron, tropisetron, ramosetron, and palonosetron.

Ramosetron is licensed only in Japan and several other Asian countries, and most studies of this drug to date have been con- ducted in Asian populations. A previous meta-analysis indicated that ramosetron has preventive effects against severe PONV [18]. However, most studies on ramosetron were conducted by Fujii, and were fiercely criticized due to fabrication of data. Mihara et al. [19] excluded Fujii's studies and performed a meta-analysis of the remaining RCTs in 2013 ( $\mathrm{n}=1,372)$, and demonstrated that ramosetron has a significant effect for preventing PONV compared with placebo, but its efficacy was less than had been reported in previous analyses. They also reported that ramosetron significantly prevented early and late postoperative vomiting compared with ondansetron, but the clinical significance was questionable because the number needed to treat was large [19].

Palonosetron represents an exciting development in the $5-\mathrm{HT}_{3}$ receptor antagonist group. Palonosetron has a unique mechanism, different from previously developed agents in this class, and has more potent and persistent effects. It has the unique pharmacodynamic characteristic of provoking a conformational change of the $5-\mathrm{HT}_{3}$ receptor through allosteric binding which is evidently distinguishable from standard $5-\mathrm{HT}_{3}$ antagonists [2]. This drug also has a much longer half-life of 40 hours, as compared to existing drugs in this class. Due to its long halflife, palonosetron is expected to reduce long-term OINV after surgery in patients using PCA. Indeed, one study has already demonstrated such results with this drug [20].

\section{Dopamine antagonists}

Dopamine receptors, particularly $\mathrm{D}_{2}$ and $\mathrm{D}_{3}$, have been shown to play important roles in inducing nausea and vomiting. The 
mechanism involves blocking adenylate cyclase to reduce the amount of CAMP in neurons in the nucleus tractus solitarius and area postrema.

\section{Metoclopramide}

Metoclopramide is a strong $\mathrm{D}_{2}$ receptor antagonist and blocks $\mathrm{H}_{1}$ and $5-\mathrm{HT}_{3}$ receptors as well as $\mathrm{D}_{2}$ receptors. This drug also blocks $\mathrm{D}_{2}$ receptors in the gastrointestinal tract and enhances $5-\mathrm{HT}_{4}$ receptors, improving prokinetic properties to induce antiemetic effects. Metoclopramide enhances motility in the upper gastrointestinal tract to promote gastric emptying without affecting gastric, biliary, or pancreatic secretion. Duodenal peristalsis is also increased, which therefore decreases intestinal transit time. This drug increases gastroesophageal sphincter tone and decreases pyloric sphincter tone and, therefore, helps to prevent delayed gastric emptying associated with opioid use.

A dose of $10 \mathrm{mg}$ of metoclopramide is commonly administered, and a recent meta-analysis showed that there were no side effects of metoclopramide, such as extrapyramidal symptoms, dizziness, headache, and sedation, at doses up to this level [21].

\section{Droperidol}

Droperidol is a relatively selective dopamine $\mathrm{D}_{2}$ receptor antagonist that potently binds the $\mathrm{D}_{2}$ receptors located in the area postrema. This drug has been shown to have PONV preventive effects, and it is as effective as ondansetron or dexamethasone. A recent meta-analysis showed that droperidol at a low dose $(<1 \mathrm{mg}$ or $<0.15 \mu \mathrm{g} / \mathrm{kg}$ ) was effective and there were no significant differences between doses of $0.25,0.625,1$, and $1.25 \mathrm{mg}$ [22].

The most common side effects of droperidol include QT prolongation and malignant ventricular arrhythmia. Four deaths occurred among seven cases in which $2.5 \mathrm{mg}$ of droperidol was administered; the other three patients survived cardiac arrest [14]. This led to the "black-box warning" by the FDA in 2001, and this drug is not used in several countries, including Korea. However, recent studies have indicated that droperidol at a low dose does not increase the risks of cardiac arrhythmia or death [23]. Nevertheless, the manufacturer recommends that the drug should not be administered in men or women with QTc intervals above $440 \mathrm{~ms}$ or above $450 \mathrm{~ms}$, respectively [14]. Therefore, care should be taken in administering this drug to patients with QTc prolongation before surgery.

\section{Phenothiazines}

The antiemetic properties of phenothiazine derivatives are attributed to their $\mathrm{D}_{2}$ receptor antagonistic actions at the CTZ. In addition, they have a histamine-blocking effect. However, these agents are not commonly used for prevention of PONV because their biological half-lives are short and they cause severe sedation.

\section{$\mathrm{NK}_{1}$ antagonist (aprepitant)}

$\mathrm{NK}_{1}$ receptor antagonists are a relatively new class of compounds developed in the early 2000s. Their activity appears to occur mainly in the nucleus tractus solitarius and possibly also areas of the reticular formation, where they potently bind to $\mathrm{NK}_{1}$ receptors that have been implicated in the emetic reflex. $\mathrm{NK}_{1}$ antagonists are known to be more effective for inhibiting emesis than nausea.

Aprepitant is the most widely used oral $\mathrm{NK}_{1}$ receptor antagonist. This drug is typically administered as a single oral dose 1-2 hours prior to surgery. One comparative study indicated a significantly lower rate of postoperative vomiting in patients treated with aprepitant, as compared to those given ondansetron, but there was no difference in nausea between the two groups [24]. Aprepitant is thought to be effective when used in a multimodal approach for PONV prevention, especially with respect to prevention of vomiting.

\section{Dexamethasone: benefit or risk?}

Due to the complex mechanism underlying the pathogenesis of PONV, two or more drugs with different mechanisms of action should be used together for its prevention. The most common combination without side effects is a combination of dexamethasone and $5-\mathrm{HT}_{3}$ receptor antagonist. In particular, dexamethasone is more effective when administered at the beginning of surgery, due to its relatively slow onset.

Despite its well-established efficacy, little is known regarding the mechanism underlying the effect of dexamethasone. Current theories focus on its antiinflammatory properties, especially with regard to decreased inflammation and edema. As expected, dexamethasone blocks the synthesis of prostaglandin which sensitizes nerves to other commonly involved neurotransmitters in emesis control. It has also been suggested that dexamethasone may have a central effect on corticosteroid receptors or $5-\mathrm{HT}_{3}$ receptors in the nucleus tractus solitarius.

There have been many studies regarding the dose of dexamethasone, and a recently published meta-analysis yielded relatively clear results. In the analysis of 60 RCTs $(n=6,696)$, dexamethasone at doses of 4-5 mg and 8-10 mg significantly decreased 24 hours PONV, as compared to the control group $\left(\mathrm{OR}=0.31,95 \% \mathrm{CI}=0.23-0.41 ; \mathrm{OR}=0.26,95 \% \mathrm{CI}=0.20^{-}\right.$ 0.32 , respectively) [25]. Thus, $8-10 \mathrm{mg}$ dexamethasone did not show clinical advantages, as compared to the lower dose of 4-5 $\mathrm{mg}$. This meta-analysis suggested that a combination of 4-5 mg dexamethasone and other antiemetics decreased the possibility of 24 hours PONV (OR $=0.50,95 \% \mathrm{CI}=0.35-0.72)$ [25], therefore supporting the efficacy of combination therapy.

A number of recent studies have indicated other additional 
effects of dexamethasone, such as pain relief or reduced systemic inflammatory reaction, in addition to PONV prevention. However, considering the relation between dexamethasone and the possibility of wound infection, whether dexamethasone can be safely used in cases of hip or knee surgery that are accompanied by a risk of wound infection that can lead to fatal deep infection, is a matter of some concern. In a recent review, Lunn and Kehlt [26] discussed the advantages and disadvantages of systemic injection of high-dose dexamethasone (>10 mg), systemic injection of low-dose dexamethasone $(<10 \mathrm{mg})$, and local injection of dexamethasone using 17 RCTs $(n=1,081)$. The PONV preventive effect was observed at both a low dose and a high dose, whereas pain relief was observed only at a high dose. Therefore, the results of a previous meta-analysis [27] indicating significant decreases in pain by dexamethasone at doses of more than 0.11 $\mathrm{mg} / \mathrm{kg}$ but not less than $0.1 \mathrm{mg} / \mathrm{kg}$ were reconfirmed. With regard to wound infection, four cases of superficial or deep knee infection were observed among 17 RCTs and all of the cases were found in the local administration group, but not in the systemic administration group [26]. The meta-analysis by Lunn and Kehlt supported previous reports showing that systemic administration did not cause significant side effects in various types of surgery other than knee or hip surgery. However, the incidence of wound infection is very low and, therefore, largescale studies on this problem are needed, given that the authors suggested that a large-scale analysis of 3,000 patients or more is required to identify stability. Nevertheless, low-dose (4-5 mg) dexamethasone, generally used for PONV prevention, may be relatively free from these complications.

\section{Others (Non-pharmacological Therapies)}

Drug administration is a priority for PONV prevention, but various studies have also indicated the beneficial effects of acupuncture, electroacupuncture, transcutaneous electrical nerve stimulation, acupoint stimulation, and acupressure [28]. However, these studies were less well-designed RCTs, as compared to those involving drug administration, and, therefore, reputable meta-analyses are rare.

\section{PONV Study}

As mentioned above, studies on PONV can be performed relatively easily due to the high incidence of PONV and ready accessibility of antiemetics. There have been many studies over the last several decades. However, many of these studies were similar and of inadequate quality. These studies included heterogeneous patient populations, insufficient sample sizes, inadequate assessment of PONV, and inconsistent definition of successful treatment. Apfel et al. [29] suggested systematic and rational guidelines through design, performance, and presentation of PONV studies. First, further studies will have to use new and appropriate drugs instead of repeatedly prophylactically given aniemetics whose main results are predictable (e.g. already proven by meta-analysis). Second, group comparability must be based on well-qualified risk factors. Studies based on numerous risk factors (e.g., body mass index, menstrual cycle), the predictability of which has not been confirmed, must be avoided. Third, an accurate sample size will have to be obtained. To achieve these goals, the concepts of relative risk and absolute risk must be clarified. In addition, patients with a PONV risk of $40 \%$ or more must be targeted to avoid pointless studies using more patients than necessary. Finally, nausea, vomiting, and rescue antiemetics must be individually reported in the results. Such well-designed RCTs will be extended to meta-analyses that will be able to provide practical clinical information.

\section{PONV-PDNV-ambulatory Surgery}

There have been a number of studies on postdischarge nausea and vomiting (PDNV), in addition to concerns about PONV, due to increasing interest in improving postoperative quality of ambulatory surgery. PDNV is included in PONV, but more closely includes nausea and vomiting occurring from 24 to 72 hours after discharge and targets patients discharged on the day of surgery. PDNV has an adverse economic effect due to delayed discharge of patients initially scheduled to be discharged on the day of surgery. Although patients are discharged on the day of surgery, rapid-onset IV antiemetic rescue medication given in a hospital cannot be provided for nausea and vomiting occurring outside the hospital. Anesthesiologists must pay attention to PDNV, considering that the number of patients discharged on the day of surgery is increasing in the minor surgery.

Risk factors of PDNV are somewhat different from those of PONV. Apfel et al. [30] conducted a large-scale prospective multicenter study including 2,170 patients, and reported five independent predictors of PDNV risk: female gender $(\mathrm{OR}=$ $1.54,95 \% \mathrm{CI}=1.22-1.94)$, age $<50$ years $(\mathrm{OR}=2.17,95 \% \mathrm{CI}=$ 1.75-2.69), history of nausea and/or vomiting after previous anesthesia $(\mathrm{OR}=1.50,95 \% \mathrm{CI}=1.19-1.88)$, opioid administration in the postanesthesia care unit $(\mathrm{OR}=1.93,95 \% \mathrm{CI}=1.53-2.43)$, and nausea in the postanesthesia care unit $(\mathrm{OR}=3.14,95 \% \mathrm{CI}$ $=2.44-4.04)$. The incidence rates of PDNV are approximately $10,20,30,50,60$, and $80 \%$ in cases with none, one, two, three, four, or five of these predictors, respectively. Therefore, if highrisk patients undergo ambulatory surgery, the anesthesiologist should consider using regional rather than general anesthesia to minimize the risk of PDNV. In cases in which regional anesthesia is not available, total intravenous anesthesia (TIVA) with propofol should be used rather than inhalation anesthetics. In 
addition, combination antiemetic therapy using a drug with a long half-life, such as palonosetron, should also be considered.

\section{Conclusions}

Although there have been a number of studies on PONV over the last several years, its incidence is still unacceptably high. This may be because development of new single antiemetics to block all mechanisms is impossible due to the complex mechanism underlying the pathogenesis of PONV. However, this may also be partially due to a relative lack of concern regarding this issue by anesthesiologists, although no accurate data are available. Some anesthesiologists often do not evaluate PONV risk factors of patients in preanesthetic examinations nor do they administer prophylactic antiemetics; they tend to easily rely on inhalation anesthetic vaporizers instead of using TIVA. This may be because PONV does not lead to fatal consequences. However, it is necessary to remember that what may be a small issue for doctors can be a major problem for patients (the big "little problem"). In addition, considering the increasing demand for ambulatory surgery, anesthesiologists must attempt a holistic approach on PONV before and during surgery. "Postoperative" attention to PONV is too late. Further studies on PONV with appropriate sample sizes, based on validated risk factors, are also required.

\section{References}

1. Kapur PA. The big "little problem". Anesth Analg 1991; 73: 243-5.

2. Horn CC, Wallisch WJ, Homanics GE, Williams JP. Pathophysiological and neurochemical mechanisms of postoperative nausea and vomiting. Eur J Pharmacol 2014; 722: 55-66.

3. Apfel CC, Läärä E, Koivuranta M, Greim CA, Roewer N. A simplified risk score for predicting postoperative nausea and vomiting: conclusions from cross-validations between two centers. Anesthesiology 1999; 91: 693-700.

4. Koivuranta M, Läärä E, Snåre L, Alahuhta S. A survey of postoperative nausea and vomiting. Anaesthesia 1997; 52: 443-9.

5. Apfel CC, Heidrich FM, Jukar-Rao S, Jalota L, Hornuss C, Whelan RP, et al. Evidence-based analysis of risk factors for postoperative nausea and vomiting. Br J Anaesth 2012; 109: 742-53.

6. Sia AT, Lim Y, Lim EC, Goh RW, Law HY, Landau R, et al. A118G single nucleotide polymorphism of human mu-opioid receptor gene influences pain perception and patient-controlled intravenous morphine consumption after intrathecal morphine for postcesarean analgesia. Anesthesiology 2008; 109: 520-6.

7. Rueffert H, Thieme V, Wallenborn J, Lemnitz N, Bergmann A, Rudlof K, et al. Do variations in the 5-HT3A and 5-HT3B serotonin receptor genes (HTR3A and HTR3B) influence the occurrence of postoperative vomiting? Anesth Analg 2009; 109: 1442-7.

8. Nakagawa M, Kuri M, Kambara N, Tanigami H, Tanaka H, Kishi Y, et al. Dopamine D2 receptor Taq IA polymorphism is associated with postoperative nausea and vomiting. J Anesth 2008; 22: 397-403.

9. Kolesnikov Y, Gabovits B, Levin A, Voiko E, Veske A. Combined catechol-O-methyltransferase and mu-opioid receptor gene polymorphisms affect morphine postoperative analgesia and central side effects. Anesth Analg 2011; 112: 448-53.

10. Hikasa Y, Ogasawara S, Takase K. Alpha adrenoceptor subtypes involved in the emetic action in dogs. J Pharmacol Exp Ther 1992; $261: 746-54$.

11. Choi EM, Lee MG, Lee SH, Choi KW, Choi SH. Association of ABCB1 polymorphisms with the efficacy of ondansetron for postoperative nausea and vomiting. Anaesthesia 2010; 65: 996-1000.

12. Wesmiller SW, Henker RA, Sereika SM, Donovan HS, Meng L, Gruen GS, et al. The association of CYP2D6 genotype and postoperative nausea and vomiting in orthopedic trauma patients. Biol Res Nurs 2013; 15: 382-9.

13. Pergolizzi JV Jr, Philip BK, Leslie JB, Taylor R Jr, Raffa RB. Perspectives on transdermal scopolamine for the treatment of postoperative nausea and vomiting. J Clin Anesth 2012; 24: 334-45.

14. Scuderi PE. Pharmacology of antiemetics. Int Anesthesiol Clin 2003; 41: 41-66.

15. Apfel CC, Korttila K, Abdalla M, Kerger H, Turan A, Vedder I, et al. A factorial trial of six interventions for the prevention of postoperative nausea and vomiting. N Engl J Med 2004; 350: 2441-51.

16. Carlisle JB, Stevenson CA. Drugs for preventing postoperative nausea and vomiting. Cochrane Database Syst Rev 2006 ; (3): CD004125.

17. Food and Drug Administration. FDA Drug Safety Communication: Abnormal Heart Rhythms may be Associated with use of Zofran (ondansetron). 2011.

18. Kim WO, Koo BN, Kim YK, Kil HK. Ramosetron for the prevention of postoperative nausea and vomiting (PONV): a meta-analysis. Korean J Anesthesiol 2011; 61: 405-12.

19. Mihara T, Tojo K, Uchimoto K, Morita S, Goto T. Reevaluation of the effectiveness of ramosetron for preventing postoperative nausea and vomiting: a systematic review and meta-analysis. Anesth Analg 2013; 117: 329-39.

20. Moon YE, Joo J, Kim JE, Lee Y. Anti-emetic effect of ondansetron and palonosetron in thyroidectomy: a prospective, randomized, doubleblind study. Br J Anaesth 2012; 108: 417-22. 
21. De Oliveira GS Jr, Castro-Alves LJ, Chang R, Yaghmour E, McCarthy RJ. Systemic metoclopramide to prevent postoperative nausea and vomiting: a meta-analysis without Fujii's studies. Br J Anaesth 2012; 109: 688-97.

22. Schaub I, Lysakowski C, Elia N, Tramer MR. Low-dose droperidol ( $\leq 1 \mathrm{mg}$ or $\leq 15 \mu \mathrm{g} \mathrm{kg}$ - 1 ) for the prevention of postoperative nausea and vomiting in adults: quantitative systematic review of randomised controlled trials. Eur J Anaesthesiol 2012; 29: 286-94.

23. Nuttall GA, Malone AM, Michels CA, Trudell LC, Renk TD, Marienau ME, et al. Does low-dose droperidol increase the risk of polymorphic ventricular tachycardia or death in the surgical patient? Anesthesiology 2013; 118: 382-6.

24. Gan TJ, Apfel CC, Kovac A, Philip BK, Singla N, Minkowitz H, et al. A randomized, double-blind comparison of the NK1 antagonist, aprepitant, versus ondansetron for the prevention of postoperative nausea and vomiting. Anesth Analg 2007; 104: 1082-9.

25. De Oliveira GS Jr, Castro-Alves LJ, Ahmad S, Kendall MC, McCarthy RJ. Dexamethasone to prevent postoperative nausea and vomiting: an updated meta-analysis of randomized controlled trials. Anesth Analg 2013; 116: 58-74.

26. Lunn TH, Kehlet H. Perioperative glucocorticoids in hip and knee surgery - benefit vs. harm? A review of randomized clinical trials. Acta Anaesthesiol Scand 2013; 57: 823-34.

27. De Oliveira GS Jr, Almeida MD, Benzon HT, McCarthy RJ. Perioperative single dose systemic dexamethasone for postoperative pain: a meta-analysis of randomized controlled trials. Anesthesiology 2011; 115: 575-88.

28. Lee A, Done ML. The use of nonpharmacologic techniques to prevent postoperative nausea and vomiting: a meta-analysis. Anesth Analg 1999; 88: 1362-9.

29. Apfel CC, Roewer N, Korttila K. How to study postoperative nausea and vomiting. Acta Anaesthesiol Scand 2002; 46: 921-8.

30. Apfel CC, Philip BK, Cakmakkaya OS, Shilling A, Shi YY, Leslie JB, et al. Who is at risk for postdischarge nausea and vomiting after ambulatory surgery? Anesthesiology 2012; 117: 475-86. 